\title{
Non-cardiac implantable electrical devices: brief review and implications for anesthesiologists
}

\section{Les appareils électriques implantables non cardiaques: courte synthèse et implications pour les anesthésiologistes}

\author{
Lashmi Venkatraghavan, MD · Vinod Chinnapa, MD • \\ Philip Peng, MBBS $\cdot$ Richard Brull, MD
}

Received: 14 October 2008/Revised: 14 January 2009/Accepted: 21 January 2009/Published online: 21 February 2009

(C) Canadian Anesthesiologists' Society 2009

\begin{abstract}
Purpose Patients with implanted electrical devices (IEDs) are vulnerable to electromagnetic interference (EMI) from electrical equipment used in the perioperative environment. As the indications for non-cardiac IEDs increase, so too does the likelihood of anesthesiologists encountering such patients who present for surgery. This article reviews the important anesthetic considerations for patients with implanted non-cardiac electrical devices.
\end{abstract}

Source We searched Medline (1980 to December 2008) and Embase (1980 to December 2008) and reviewed all relevant manuscripts regarding non-cardiac IEDs and anesthesia.

Principal findings There are numerous non-cardiac IEDs currently in use, including deep brain stimulators, vagal nerve stimulators, gastric stimulators, phrenic nerve stimulators, sacral nerve stimulators, and bone stimulators. A key goal in the perioperative management of these patients is to reduce the risk of adverse events resulting from device interactions with electrocautery, external emergency cardiac defibrillation, peripheral nerve stimulation, neuraxial anesthesia, and magnetic resonance imaging. We offer a general management strategy for patients with IEDs presenting for surgery.

Conclusions In the absence of available anesthesia management guidelines regarding non-cardiac IEDs in the perioperative setting, anesthesiologists should appreciate

L. Venkatraghavan, MD $(\varangle) \cdot$ V. Chinnapa, MD .

P. Peng, MBBS · R. Brull, MD

Department of Anesthesia and Pain Management, Toronto

Western Hospital, University Health Network, 399 Bathurst

Street, Toronto M5T 2S8, ON, Canada

e-mail: Lashmi.venkatraghavan@uhn.on.ca the basic principles pertaining to IEDs to ensure appropriate risk reduction strategies in order to enhance patient safety.

\section{Résumé}

Objectif Les patients qui ont un appareil electrique implanté (IED) sont vulnérables aux interférences électromagnétiques (EMI) provenant des appareils électriques utilisés dans l'environnement périopératoire. Alors que les indications pour l'implantation d'IED non cardiaques s'étendent, la probabilité que les anesthésiologistes rencontrent de tels patients se présentant pour une chirurgie augmente elle aussi. En l'absence de littérature pertinente ou de directives pour l'anesthésie, cet article tente de passer en revue les considérations anesthésiques importantes concernant les patients munis d'appareils électriques implantés non cardiaques.

Source Nos recherches ont porté sur les bases de données Medline (1980 à décembre 2008) et Embase (1980 à décembre 2008) et nous avons passé en revue tous les manuscrits pertinents concernant les IED non cardiaques et l'anesthésie.

Constatations principales Il existe de nombreux IED non cardiaques, notamment des stimulateurs cérébraux profonds, des stimulateurs du nerf vague, des stimulateurs gastriques, des stimulateurs du nerf phrénique, des stimulateurs du nerf sacré et des stimulateurs osseux. La prise en charge périopératoire a pour but de réduire le risque d'effets secondaires provenant de l'interaction de ces appareils avec l'électrocautère, la défibrillation cardiaque externe d'urgence, la stimulation de nerfs périphériques, l'anesthésie neuraxiale et l'imagerie par résonance magnétique. Nous proposons une stratégie générale de prise en charge des patients ayant un IED et devant subir une chirurgie. 
Conclusion En l'absence de directives de prise en charge de l'anesthésie concernant les IED non cardiaques dans un contexte périopératoire, les anesthésiologistes devraient être conscients des principes de base concernant les IED et ce, afin de garantir que des stratégies adéquates de réduction des risques soient mises en place pour améliorer la sécurité des patients.

Since the introduction of the cardiac pacemaker into clinical medicine, there has been a growing interest in the clinical applications of electrotherapy and neuromodulation and also in the research relating to this speciality. This pursuit has led to the development of several non-cardiac implantable electrical stimulation devices. ${ }^{1}$ These implantable electrical devices (IED) provide a number of treatment options in many diseases that cannot be managed by medication alone. The most common examples of implantable non-cardiac electrical devices include spinal cord stimulators (SCS), deep brain stimulators (DBS), vagal nerve stimulators (VNS), and sacral nerve stimulators. With the growing popularity of such devices, anesthesiologists are increasingly likely to encounter patients with such devices in situ presenting for surgery.

Understanding the potentially adverse effects of electromagnetic interference regarding these devices is paramount to safe anesthetic management. Specifically, interaction with common medical equipment, namely, electrocautery, defibrillators, magnetic resonance imaging (MRI), and peripheral nerve stimulators (PNSs) has the potential to cause serious injury. Unfortunately, there is a paucity of literature on the subject of perioperative management of patients with non-cardiac IEDs. We undertook a literature review to provide an update concerning the clinical functioning, operating mechanisms, anatomical location, clinical indications, potential complications, and anesthetic implications of IEDs. The review does not address perioperative care of patients undergoing surgery for implantation of such electrical devices.

\section{Search strategy}

The literature search for this review was conducted in December 2008 using MEDLINE (1980 to Dec 2008) and EMBASE (1980 to Dec 2008) to include the following search terms: "Implantable electrical device," "General Anesthesia," Regional Anesthesia," "Diathermy," "Deep Brain Stimulator," "Vagal Nerve Stimulator," "Spinal cord stimulators," "Neuro stimulator and pacemakers." The search was limited to human studies and English language. The bibliography of each article was then reviewed to seek additional articles.

Implantable electrical devices

In general, IEDs are comprised of three components. The first component is the pulse generator, which is battery powered and can be externally programed by either the patient or the physician. The second component consists of electrodes designed for implantation in the target neural tissue. The electrodes are of different sizes, lengths, and design, as required for percutaneous insertion or surgical implantation. The third component is the cable connecting the pulse generator to the electrodes. Individual devices vary with respect to location of the pulse generators and their programability.

\section{Deep brain stimulator}

Deep brain stimulation is a minimally invasive, targeted neurosurgical intervention that enables structures deep within the brain to be stimulated electrically by an implanted pacemaker. ${ }^{2}$ Since its success with Parkinson's disease, the scope of DBS has been expanded to other movement disorders (tremors, tics, and dystonias), psychiatric illness (major depression, obsessive-compulsive disorder), chronic pain, and refractory epilepsy. ${ }^{3}$ The most common targets for stimulation include the thalamus, the globus palladium, and the subthalamic nuclei. ${ }^{4}$ To place the stimulating electrode(s) in the targeted area, the surgeon uses a stereotactic frame with CT/MRI guidance, as well as other techniques, such as microelectrode recordings with stimulation testing of an awake patient. The wire electrodes are then tunnelled subcutaneously from the head and neck to the chest wall where they are attached to a pulse generator. Adjustable settings of the pulse generator include electrode selection, stimulation pulse amplitude, pulse width, and frequency. The patient may turn the device on or off and may switch between settings by using an external magnet. ${ }^{5}$ In addition, clinicians can also adjust stimulation parameters via telemetry to meet each patient's individual needs.

Vagal nerve stimulator

In 1997, the US Food and Drug Administration (FDA) approved the use of VNS for the management of medically refractory epilepsy. Since then, approximately 32,000 people with epilepsy have been treated with this device. The postulated mechanism of action involves the stimulation of afferent vagal nerve fibers that modulate cerebral neuronal excitability through the activation of either the limbic system or the noradrenergic neurotransmitter 
system, or through generalized brain stem arousal. ${ }^{6,7}$ The vagal nerve stimulation generator is inserted subcutaneously below the left clavicle. The electrode is implanted into the left vagal nerve. This procedure is typically performed under general anesthesia. ${ }^{8}$ The external programing system includes the programing wand or magnet, the software, and the compatible computer.

\section{Sacral nerve stimulator or bladder stimulator}

Sacral nerve stimulation was initially used for urinary incontinence in patients with severe neurological disease. ${ }^{9}$ However, the indications for sacral nerve stimulation have since been expanded to include neurogenic refractory urge incontinence, interstitial cystitis, pelvic pain, and fecal incontinence. ${ }^{10}$ Following a trial with a temporary stimulator that paces the bladder externally through the skin, patients with favorable results undergo surgical implantation of the permanent device, which consists of a lead wire containing four platinum electrodes. The wire is inserted surgically into the sacral foramen at $\mathrm{S} 3$ on one side adjacent to the sacral nerve. The generator itself is implanted subcutaneously in the hip area. ${ }^{11}$

\section{Phrenic nerve stimulator or diaphragmatic pacemaker}

A diaphragmatic pacemaker electrically stimulates the phrenic nerve to cause rhythmic contraction of the diaphragm. ${ }^{12},{ }^{13}$ Since its approval by the FDA in 1987, this device has been used to treat hundreds of patients with respiratory failure due to high cervical cord injury $(\mathrm{C} 1-\mathrm{C} 2)$ or respiratory center dysfunction (central alveolar hypoventilation). ${ }^{14}$ Successful implantation of the diaphragm pacemaker relies on an intact phrenic nerve and a functional diaphragm. Hence, patients with lesions of the phrenic nerve, its nucleus, or weakness of the diaphragm are not suitable candidates. ${ }^{12,13}$ Surgical implantation of a diaphragmatic pacemaker is usually performed laparoscopically. Four electrodes are implanted in each phrenic nerve. A receiver implanted in the subcutaneous tissue is connected to the electrodes by platinum leads. An external portable battery-operated transmitter generates radio waves, which are converted to an electrical stimulus by the receiver. ${ }^{14}$ The amount of electrical voltage is proportional to diaphragm contraction or tidal volume. The transmitter controls the frequency of breaths, tidal volume, pulse interval, pulse width, and slope of pulse. ${ }^{12}$

Spinal cord stimulator

The SCS was first introduced in the 1960s. The common indications for spinal cord stimulation include failed back surgery syndrome (FBSS), complex regional pain syndromes (CRPS), peripheral vascular disease, and refractory angina. ${ }^{15,16}$ Patients selected for this therapy are those who are refractory to conventional medical and surgical therapies. Though multiple mechanisms have been explored, the exact mechanism activating SCS is poorly understood. ${ }^{17}$ In general, a trial insertion of an electrode is performed through either the percutaneous route or a laminectomy. The electrode is then connected to an external programer. If the patient is selected as a candidate, an internal pulse generator is implanted as a separate procedure. The site of electrode placement depends on the site of pain. In general, the electrode is placed at the T9-L1 level for lower limb pain, $\mathrm{C} 6$ to $\mathrm{T} 2$ for angina, and $\mathrm{C} 4$ to $\mathrm{T} 1$ for upper limb pain. ${ }^{17,18}$

\section{Gastric pacemaker}

In 2000, gastric electrical stimulation (GES) was approved by the FDA for the treatment of gastroparesis refractory to medical therapy. ${ }^{19}$. Control of gastric motility by myoelectric activity is the basis for use of GES in gastroparesis. ${ }^{20}$ Gastric pacing generates high frequency stimuli that enhance motility and facilitate emptying. However, the exact mechanisms underlying gastric pacing are not fully understood. Two bipolar leads are implanted laparoscopically into the muscle wall of the stomach and then joined with a subcutaneous electrical stimulator, which is usually placed in the upper abdomen. A programing device is used to control and adjust the settings of the neurostimulator.

\section{Bone stimulator}

Electrical bone stimulation can be used to enhance bone growth. The relationship of electrical stimulus and bone growth is based on scientific experiments that reported the inherent bioelectrical property of bone. It has been shown that bone modifies its structure in response to an electrical stimulus. This led to development of bone stimulators to promote healing. ${ }^{21}$ The primary indication for bone stimulators have been for non-union or delayed unions. Failed arthrodesis and spinal fusion have since been added as indications. $^{22}$ Bone stimulators can be subdivided into invasive and non-invasive categories. The non-invasive device, which uses an electromagnetic field to stimulate bone growth, consists of a generator and electrodes attached to the surface of skin. The invasive technique, which uses direct current, involves surgical implantation of electrodes at the desired site for bone growth. The negative electrodes are placed at the site where bone repair is desired and a positive electrode is placed in the soft tissue. A generator is placed in nearby subcutaneous tissue or in an intramuscular plane. 
Laryngeal nerve stimulator

Laryngeal pacing devices are used to prevent aspiration by causing dynamic laryngotracheal closure. ${ }^{23}$ Stroke-related dysphagia affects approximately 500,000 patients in the United States, and half of these patients experience aspiration. ${ }^{24}$ First described in 2001, the device consists of bipolar electrodes implanted surgically into a recurrent laryngeal nerve and a receiver-stimulator implanted subcutaneously. Activation of the stimulator is performed through an external transmitter. When swallowing is initiated, the stimulator is activated causing glottic closure, thus preventing aspiration.

\section{Perioperative management}

Currently, there are no guidelines for the perioperative care of patients with implantable non-cardiac electrical devices. In addition to potential interactions of IED with other medical devices, the actual disease process for which the IED was inserted (e.g., Parkinson's disease, chronic pain, refractory epilepsy, and chronic spinal cord injury) can render the perioperative care of these patients difficult. The Association of Operating Room Nurses $($ AORN) provides a general guidance statement on the perioperative care of patients with implanted electrical devices. ${ }^{25}$ Based on the available literature, the AORN guidance statement, and the manufacturers' manuals, we suggest the following risk reduction strategy for the perioperative care of patients with non-cardiac implantable pacemakers or stimulators.

\section{General considerations}

Preoperative period

All patients with non-cardiac IEDs should be seen in the anesthesia consult clinic prior to surgery. The preoperative assessment should focus on both the IED and the medical condition for which the IED is indicated. Similar to cardiac pacemakers and defibrillators, the following information should be collected and documented in the medical chart:

- Type and location of non-cardiac IED

- Date of implantation and last check

- Anesthetic complications during insertion

- Current status of IED in terms of symptoms control

- Programability of the device (turning off)

- Severity of symptoms when the device is turned off

- Current medications
In addition, the physician who implanted the IED should be made aware of the upcoming surgery. The anesthesiologist should discuss the management plan with the physician regarding the perioperative care of these patients. The discussion should focus on safety concerns and equipment conflicts, programing the device, medication changes when the IED is turned off, and postoperative evaluation of the IED. The appropriate industry representative should be contacted, and arrangements should be made for his/her presence during the perioperative period.

\section{Intraoperative period}

All operating room personnel should be notified that the patient has an IED and should review potential safety concerns and equipment conflicts which may affect the proper functioning of IEDs. The programing module and the appropriate medical and/or industry personnel should be present in the operating room before the start of surgery. To reduce the possibility of creating static electricity in the environment, the humidity and temperature in the operating room should be maintained within recommended ranges. The temperature in the operating room should be between 20 and $24^{\circ} \mathrm{C}$ ( 68 and $76^{\circ} \mathrm{F}$ ), and the humidity should be between $50 \%$ and $60 \% .^{25}$ Patients can suffer serious injuries as a result of device interactions. These devices may include electrocautery, external or implanted cardiac pacemakers, external or implanted defibrillators, PNSs, and magnetic resonance imaging (MRI).

\section{Device interactions}

\section{Electrocautery}

According to the manufacturers' technical manuals, the use of diathermy is contraindicated in patients with deep brain, bladder, gastric, phrenic nerve, and SCSs. There are two case reports of serious brain tissue damage with the use of diathermy in patients with DBS. ${ }^{26,27}$ Although this is alarming, it is important to note that the diathermy referred to in the IED technical manual and case reports is not the conventional surgical electrocautery but includes shortwave diathermy, microwave diathermy, and therapeutic ultrasound. Diathermy refers to the generation of local heat in body tissues for therapeutic purposes. Many allied health professionals, such as physiotherapists, chiropractors, and sports injury therapists, routinely use diathermy to treat a wide variety of conditions. Diathermy that uses short wave, microwave, or ultrasound energy can cause permanent nerve or tissue damage in patients with a neurostimulator, even if this device is switched off. Electrocautery that is used in routine surgical practice can also damage the leads and can cause temporary suppression of neurostimulator 
output and/or reprograming of the device. The manufacturers' recommendations for safe use of electrocautery in patients with non-cardiac IEDs are similar to those for cardiac pacemakers and include avoiding electrocautery and using bipolar rather than unipolar electrocautery. If unipolar electrocautery is mandated, the ground plate should be kept as far away as possible from the pulse generator and the leads. ${ }^{26,27}$

\section{Emergency external defibrillation}

Anesthesiologists may also encounter the need of external defibrillation in patients with an IED. It is known that external cardioversions and defibrillations deliver large amounts of electrical energy to cardiac pacemakers and can damage the cardiac pulse generator. ${ }^{28,29}$ However, the literature on external defibrillation in patients with non-cardiac IEDs is sparse. In this context, if external cardioversion or defibrillation is needed, several steps should be taken to minimize the electrical current flowing through the neurostimulator. First, position the paddles as far away as possible from the IED. Second, position the paddles perpendicular to the IED; use the lowest clinically appropriate output setting, and, finally, confirm that the IED is functioning properly after defibrillation.

\section{Peripheral nerve stimulation}

Peripheral nerve stimulators used for nerve localization during peripheral nerve block may interfere with the performance of IEDs. There are two published case reports describing the use of PNS in patients with IEDs. One involved the interaction with a cardiac pacemaker, and the other involved a non-cardiac implantable electrical device (DBS) ${ }^{30,31}$ Englehardt et al. reported a case of cardiac pacemaker malfunction with the use of a PNS. In this case, the use of a PNS with pulse duration of $1 \mathrm{~ms}$ led to complete but transient inhibition of a permanently implanted pacemaker. No inhibition was observed during nerve stimulation with pulse duration of $0.1 \mathrm{~ms} .{ }^{31}$ In the other case report involving the use of a nerve stimulator for supraclavicular block, there was no interference with the DBS and no resulting complication. ${ }^{30}$

There are several safety precautions which should be considered during peripheral nerve blocks in patients with implantable electrical devices. ${ }^{32}$ First, apply the electrical current in such a fashion that it will not cross the pulse generator and the lead system. Second, avoid high pulse duration and high frequency. Alternatively, it has been recommended to use ultrasound guidance for localizing the peripheral nerve. ${ }^{33}$

\section{Neuroaxial anesthesia}

Spinal anesthesia is not contraindicated in patients with a SCS or a sacral nerve stimulator. The electrode placement site for the SCS is adjacent to the cord level ( $\mathrm{L} 1$ or above); the electrode placement site for the sacral nerve stimulator is adjoining the sacral nerve root, and the insertion site for the spinal needle is generally between L1 and L5. However, before attempting any spinal anesthesia, the clinician should obtain an X-ray or an operative record of the stimulator system, as the stimulator entry site and the course of the connecting cable may be in the spinal needle insertion region. For instance, the insertion site for the SCS can be as low as the interlaminar space of L2-3. In that case, the needle insertion should be below that level to avoid damaging the electrode. The situation is different for the insertion of an epidural catheter, which can potentially reach a higher level above the needle insertion site. Thus, the clinician should avoid the use of a lumbar epidural catheter when the electrode is in the lower lumber segment. Exceptions to the above guidelines would be situations where the stimulator electrode is quite remote from the epidural insertion site, such as a lumber epidural catheter for insertion in a patient with a cervical stimulator electrode, or situations where there is a high epidural catheter in a patient with a low stimulator electrode. ${ }^{34}$

\section{Magnetic resonance imaging safety}

The subject of MRI compatibility with DBS and other IEDs is a source of intense and ongoing controversy. The principal MRI safety concerns for electrical stimulation devices include heating at the tissue level, magnetic field interaction, induced electrical currents, and functional disruption of the operational aspects of these devices. ${ }^{35}$ Two case reports in the literature describe serious injury after MRI in patients with DBS. In both patients, serious adverse events occurred during scanning that was performed outside the guidelines provided by the device manufacturers. ${ }^{36,37}$ However, case reports in patients undergoing MRI with a VNS, sacral nerve stimulator, and bladder pacemaker have proven to be successful when specific precautions were undertaken. ${ }^{38,39}$ In general, there is a wide variation in the spectrum of MRI techniques used at different institutions, implying that every patient with an implanted stimulator device should be evaluated on an individualized basis in order to maximize patient safety. ${ }^{11}$

\section{Device-specific considerations}

Among all the non-cardiac IEDs, VNS are unique because of adverse effects pertaining to chronic vagal nerve stimulation. The common respiratory side effects of chronic 
vagal stimulation include dyspnea on exertion, altered breathing patterns (gasping), snoring during sleep, decreased airflow, and heightened respiratory effort during sleep. ${ }^{40-42}$ In addition, one-third of patients with refractory epilepsy may have baseline obstructive sleep apnea (OSA). ${ }^{43}$ A combination of respiratory side effects of chronic vagal nerve stimulation, residual anesthetic effects, and concomitant OSA may increase the risk of postoperative respiratory compromise.

The vagus nerve supplies sensory and motor innervation to the pharynx and larynx. It has been shown that chronic vagal stimulation can cause laryngopharyngeal dysfunction and risk of aspiration of gastric contents. In addition, abnormal motion of the vocal cords resulting from vagal stimulation can cause partial airway obstruction during general anesthesia in patients with a laryngeal mask airway. ${ }^{44}$ Trauma to vocal cords has been reported in patients managed with an endotracheal tube, as the VNS intermittently adducts the vocal fold against the rigid endotracheal tube. ${ }^{45}$ Another major effect of chronic vagal stimulation includes changes in heart rate variability due to changes in the sympatho-vagal balance in the heart. ${ }^{46,47}$ No study has reported clinically relevant arrhythmias or cardiac side effects related to chronic VNS. ${ }^{48,49}$

\section{Postoperative period}

All patients should be examined postoperatively for potential damage in and around the location of the IED, and the IED should be evaluated and reprogramed by appropriately qualified individuals.

\section{Conclusions}

As the indications for non-cardiac IEDs continue to increase, so too does the likelihood that anesthesiologists will encounter patients with such devices presenting for related or unrelated surgery. In the absence of available anesthesia management guidelines regarding non-cardiac IEDs in the perioperative setting, anesthesiologists should appreciate the basic principles pertaining to IEDs to ensure appropriate risk reduction strategies in order to enhance patient safety.

Conflict of interest Dr. Peng has received a research grant from Medtronic Canada Inc. None of the authors has any competing interests in relation to this article.

\section{References}

1. Krames ES. Neuromodulatory devices are part of our "tools of the trade". Pain Med 2006; 7: S3-5.
2. Pereira EA, Green AL, Nandi D, Aziz TZ. Deep brain stimulation: indications and evidence. Expert Rev Med Devices 2007; 4: 591603.

3. Gross RE. Deep brain stimulation in the treatment of neurological and psychiatric disease. Expert Rev Neurother 2004; 4: 465-78.

4. Krause M, Fogel W, Heck A, et al. Deep brain stimulation for the treatment of Parkinson's disease: subthalamic nucleus versus globus pallidus internus. J Neurol Neurosurg Psychiatry 2001; 70: 464-70.

5. Martinelli PT, Schulze KE, Nelson BR. Mohs micrographic surgery in a patient with deep brain stimulator: a review of the literature on implantable electrical devices. Dermatol Surg 2004; 30: 1021-30.

6. McLachlan RS. Vagus nerve stimulation for intractable epilepsy: a review. Clin Neurophysiol 1997; 14: 358-68.

7. Henry TR. Therapeutic mechanisms of vagus nerve stimulation. Neurology 2002; 59: S3-14.

8. Hatton KW, McLarney JT, Pittman T, Fahy BG. Vagal nerve stimulation: overview and implications for anesthesiologists. Anesth Analg 2006; 103: 1241-9.

9. Jezernik S, Craggs M, Grill WM, Creasey G, Rijkhoff NJ. Electrical stimulation for the treatment of bladder dysfunction: current status and future possibilities. Neurol Res 2002; 24: 413-30.

10. Peeren $F$, Hoebeke $P$, Everaert $K$. Sacral nerve stimulation: interstim therapy. Expert Rev Med Devices 2005; 2: 253-8.

11. Levin G, Ortiz AO, Katz DS. Noncardiac implantable pacemakers and stimulators: current role and radiographic appearance. Am J Roentgenol 2007; 188: 984-91.

12. Garcia-Morato J, De Vito EL. Diaphragmatic pacing in neuromuscular respiratory failure. Clin Pulmonary Med 2004; 11: 25-32.

13. Moxham J, Shneerson JM. Diaphragmatic pacing. Am Rev Respir Dis 1993; 148: 533-6.

14. Chen ML, Tablizo MA, Kun S, Keens TG. Diaphragm pacers as a treatment for congenital central hypoventilation syndrome. Expert Rev Med Devices 2005; 2: 577-85.

15. Peng PW, Fedoroff I, Jacques L, Kumar K. Survey of practice of spinal cord stimulator and intathecal analgesic delivery implants for the management of pain in Canada. Pain Res Manag 2007; 12: $281-5$.

16. Cameron T. Safety and efficacy of spinal cord stimulation for the treatment of chronic pain: a 20 -year literature review. J Neurosurg 2004; 100: 254-67.

17. Linderoth B, Foreman RD. Mechanism of spinal cord stimulation in painful syndromes: role of animal models. Pain Med 2006; 7 : S14-26.

18. Kemler MA, Barendse GA, van Kleef $M$, et al. Spinal cord stimulation in patients with chronic reflex sympathetic dystrophy. N Engl J Med 2000; 343: 618-24.

19. Lin Z, Forster J, Sarosiek I, McCallum RW. Treatment of gastroparesis with electrical stimulation. Dig Dis Sci 2003; 48: 837-48.

20. Li FY, Jiang LS, Cheng JQ, Mao H, Li N, Cheng NS. Clinical application prospects of gastric pacing for treating postoperative gastric motility disorders. J Gastroenterol Hepatol 2007; 22: 2055-9.

21. Anglen J. The clinical use of bone stimulators. J South Orthop Assoc 2003; 12: 46-54.

22. Paterson DC, Lewis GN, Cass CA. Treatment of delayed union and nonunion with an implanted direct current stimulator. Clin Orthop Relat Res 1980; 148: 117-28.

23. Broniatowski M, Grundfest-Broniatowski S, Tyler DJ, et al. Dynamic laryngotracheal closure for aspiration: a preliminary report. Laryngoscope 2001; 111: 2032-40.

24. Johnson R, Mckenzie S, Sievers A. Aspiration pneumonia in stroke. Arch Phys Med Rehabil 1993; 74: 973-6.

25. Association of periOperative Registered Nurses. AORN guidance statement: care of the perioperative patient with an implantable electronic device. AORN J 2005; 82: 74-82. 
26. Nutt JG, Anderson VC, Peacock JH, Hammerstad JP, Burchiel $K J$. DBS and diathermy interaction induces severe CNS damage. Neurology 2001; 56: 1384-6.

27. Dommerholt J, Issa T. DBS and diathermy interaction induces severe CNS damage. Neurology 2001; 57: 2324-5.

28. Davies $R G$. Deep brain stimulators and anaesthesia. Br J Anaesth 2005; 95: 424.

29. Allen $M$. Pacemakers and implantable cardioverter defibrillators. Anaesthesia 2006; 61: 883-90.

30. Minville V, Chassery C, Benhaoua A, Lubrano V, Albaladejo P, Fourcade $O$. Nerve stimulator-guided brachial plexus block in a patient with severe Parkinson's disease and bilateral deep brain stimulators. Anesth Analg 2006; 102: 1296.

31. Engelhardt L, Grosse J, Birnbaum J, Volk T. Inhibition of a pacemaker during nerve stimulation for regional anaesthesia. Anaesthesia 2007; 62: 1071-4.

32. McKay RE, Rozner MA. Preventing pacemaker problems with nerve stimulators. Anaesthesia 2008; 63: 554-6.

33. Manickam B, Brull R. The implications of an implanted cardiac pacemaker in peripheral nerve blockade. Reg Anesth Pain Med (in press).

34. Hanson JL, Goodman EJ. Labor epidural placement in a woman with a cervical spinal cord stimulator. Int J Obst Anesth 2006; 15 : 246-9.

35. Rezai AR, Baker KB, Tkach JA, et al. Is magnetic resonance imaging safe for patients with neurostimulation systems used for deep brain stimulation? Neurosurgery 2005; 57: 1056-62.

36. Henderson JM, Tkach J, Phillips M, Baker K, Shellock FG, Rezai $A R$. Permanent neurological deficit related to magnetic resonance imaging in a patient with implanted deep brain stimulation electrodes for Parkinson's disease: case report. Neurosurgery 2005; 57: E1063.

37. Spiegel J, Fuss G, Backens $M$, et al. Transient dystonia following magnetic resonance imaging in a patient with deep brain stimulation electrodes for the treatment of Parkinson disease. Case report. J Neurosurg 2003; 99: 772-4.

38. Benbadis SR, Nyhenhuis J, Tatum WO IV, Murtagh FR, Gieron $M$, Vale $F L$. MRI of the brain is safe in patients implanted with the vagus nerve stimulator. Seizure $2001 ; 10$ : 512-5.
39. Elkelini MS, Hassouna MM. Safety of MRI at 1.5 Tesla in patients with implanted sacral nerve neurostimulator. Eur Urol 2006; 50: 311-6.

40. Nagarajan L, Walsh P, Gregory P, Stick S, Maul J, Ghosh S. Respiratory pattern changes in sleep in children on vagal nerve stimulation for refractory epilepsy. Can J Neurol Sci 2003; 30: 224-7.

41. Banzett RB, Guz A, Paydarfar D, Shea SA, Schachter SC, Lansing $R W$. Cardiorespiratory variables and sensation during stimulation of the left vagus in patients with epilepsy. Epilepsy Res 1999; 35: $1-11$.

42. Malow BA, Edwards J, Marzec M, Sagher O, Fromes G. Effects of vagus nerve stimulation on respiration during sleep: a pilot study. Neurology 2000; 55: 1450-4.

43. Ramani $R$. Vagus nerve stimulation therapy for seizures. J Neurosurg Anesthesiol 2008; 20: 29-35.

44. Bernards $C M$. An unusual cause of airway obstruction during general anesthesia with a laryngeal mask airway. Anesthesiology 2004; 100: 1017-8.

45. Zumsteg D, Jenny D, Wieser $H G$. Vocal cord adduction during vagus nerve stimulation for treatment of epilepsy. Neurology 2000; 54: 1388-9.

46. Setty AB, Vaughn BV, Quint SR, Robertson KR, Messenheimer $J A$. Heart period variability during vagal nerve stimulation. Seizure 1998;7:213-7.

47. Kamath $M V$, Upton AR, Talalla A, Fallen EL. Effect of vagal nerve electrostimulation on the power spectrum of heart rate variability in man. Pacing Clin Electrophysiol 1992; 15: 235-43.

48. Tatum WO IV, Moore DB, Stecker MM, et al. Ventricular asystole during vagus nerve stimulation for epilepsy in humans. Neurology 1999; 52: 1267-9.

49. Asconape JJ, Moore DD, Zipes DP, Hartman LM, Duffell WH Jr. Bradycardia and asystole with the use of vagus nerve stimulation for the treatment of epilepsy: a rare complication of intraoperative device testing. Epilepsia 1999;40:1452-4. 